Sains Malaysiana 49(1)(2020): 69-74

http://dx.doi.org/10.17576/jsm-2020-4901-08

\title{
Penyahwarnaan Efluen Kilang Minyak Kelapa Sawit (POME) melalui Proses Pengoksidaan Fenton secara Berterusan menggunakan Limonit sebagai Pemangkin \\ (Palm Oil Mill Effluent (POME) Decolorize through Continuous Fenton Oxidation Process using Limonite as Catalyst)
}

\author{
Nur Fazlinda Razali, Chin Hua Chia*, Sarani Zakaria, Mohd Shaiful Sajab, \\ TATSUYA TOBE \& MiKu TSUDA
}

\begin{abstract}
ABSTRAK
Industri minyak sawit mempunyai impak yang besar ke atas alam sekitar terutama di Malaysia. Efluen kilang minyak sawit (POME) merupakan air buangan yang mengandungi sebatian organik yang berasal daripada bahan boleh urai dan sedia direput oleh mikroorganisma. Teknologi rawatan POME masa kini banyak bertumpu kepada kaedah biologi untuk mengurangkan permintaan oksigen kimia (COD), permintaan oksigen bio-kimia (BOD) dan jumlah karbon organik (TOC). Walau bagaimanapun, kebanyakan proses biologi tidak dapat menguraikan warna yang terdapat dalam POME. Kajian ini mengkaji potensi teknologi pengoksidaan Fenton menggunakan biji limonit sebagai pemangkin kepada hidrogen peroksida untuk merawat POME selepas proses rawatan biologi yang diperoleh daripada kilang minyak kelapa sawit. Keputusan menunjukkan dengan hanya $50 \mathrm{mM} \mathrm{H}_{2} \mathrm{O}_{2}$ boleh menyahwarnakan POME sebanyak 800-1000 PtCo secara berterusan dengan pengekalan masa 1 jam pada $\mathrm{pH} 3$.
\end{abstract}

Kata kunci: Limonit; pengoksidaan Fenton; POME; sistem kolum berterusan; warna

ABSTRACT

Palm oil industry has huge impact on the environment especially in Malaysia. The palm oil mill effluent (POME) is a liquid waste that contains organic compounds derived from degradable material and was easily decomposed by microorganisms. Today's POME treatment technology relies heavily on biological methods to reduce chemical oxygen demand (COD), biochemical oxygen demand (BOD) and total organic carbon (TOC). However, these processes cannot decompose the color compounds found in POME. This study describes a study on potential uses of Fenton oxidation using limonite ore as catalyst to treat POME after biological treatment which was obtained from a palm oil mill. The results showed that only $50 \mathrm{mM}$ of $\mathrm{H}_{2} \mathrm{O}_{2}$ could decolorize 800 - 1000 PtCo of the POME via continuous treatment with 1 hour retention time at $\mathrm{pH} 3$.

Keywords: Limonite; colour; continuous column system; Fenton oxidation; POME

\section{Pendahuluan}

Malaysia merupakan pengeluar kedua terbesar minyak sawit di dunia. Akibat daripada pengeluaran yang begitu besar, sejumlah besar efluen minyak sawit telah dihasilkan daripada kilang minyak kelapa sawit setiap hari. Proses pengesktrakan minyak sawit termasuklah penekanan, pensterilan, pencernaan, pelucutan, pembersihan dan pengeringan vakum (Alhaji et al. 2016) menggunakan kuantiti air yang sangat banyak (Aris et al. 2008). Sejumlah 44 juta tan POME dihasilkan di Malaysia dan angka tersebut dijangka akan meningkat setiap tahun (Wu et al. 2010).

POME adalah cecair berwarna coklat pekat yang mempunyai pepejal terampai yang terdiri daripada pelbagai bahan organik dan bukan organik, seperti lignin, tannin, lipid dan asid lemak (Saeed et al. 2015). Warna kekeruhan akibat daripada bahan-bahan tersebut menyebabkan POME sukar untuk terbiodegradasi. Disebabkan ciri fizikal dan kimia POME dan isi padu POME yang besar, ia memerlukan satu rawatan yang lebih berkesan untuk mengurangkan kandungan pencemaran supaya menepati piawaian. Rawatan POME telah dibangunkan sejak sedekad yang lalu. Kaedah yang biasa digunakan adalah sistem takungan kolam termasuk penyejukan, anaerobik, aerobik, fakultatif dan kolam alga, sebelum efluen dilepaskan ke dalam sungai (Othman et al. 2014). Untuk peringkat rawatan ketiga, iaitu sebelum dilepaskan ke sungai, teknologi penapisan membran kerap digunakan iaitu proses fizikal pilihan untuk mengasingkan molekul bersaiz tertentu (Nik Sulaiman \& Chea 2004)

Pada masa ini, sistem takungan terbuka digunakan untuk merawat POME di seluruh negara. Walau bagaimanapun, terdapat beberapa kelemahan dalam sistem takungan terbuka, termasuk masa rawatan yang panjang, memerlukan kawasan tanah yang luas serta penghasilan gas metana yang menyebabkan kesan rumah hijau (Saeed et al. 2015). Kajian lepas telah membuktikan bahawa warna efluen adalah sukar dirawat disebabkan oleh sebatian fenol yang terdapat dalam POME dan turut menyebabkan POME 
berwarna kekeruhan (Kietkwanboot et al. 2015; Neoh et al. 2014). Walaupun warna efluen bukan suatu ciri yang perlu dipantau oleh pengilang minyak kelapa sawit, tapi untuk tempoh masa yang panjang, pencemaran air tetap akan berlaku. Pelbagai rawatan telah dilakukan untuk merawat warna efluen, iaitu penggumpalan (Bhatia et al. 2007) dan penyerapan (Sajab et al. 2014), tetapi ia hanya menukarkan POME daripada fasa cecair kepada fasa pepejal (Aris et al. 2008).

Proses pengoksidaan Fenton merupakan sejenis rawatan yang telah dikaji oleh ramai penyelidik disebabkan oleh kebolehan untuk mendegradasikan sebatian organik dalam air buangan. Radikal hidroksil $(\mathrm{OH} \bullet)$ yang mempunyai kereaktifan yang tinggi untuk mengurai sebatian organik, seperti yang ditunjukkan dalam (1) dan (2) (Pereira et al. 2012):

$$
\begin{aligned}
& \mathrm{Fe}^{2+}+\mathrm{H}_{2} \mathrm{O}_{2} \rightarrow \mathrm{Fe}^{3+}+\cdot \mathrm{OH}+\mathrm{OH}^{-} \\
& \mathrm{Fe}^{3+}+\mathrm{H}_{2} \mathrm{O}_{2} \rightarrow \mathrm{Fe}^{2+}+\mathrm{HO}_{2} \cdot+\mathrm{H}^{+}
\end{aligned}
$$

Dalam kajian ini, POME yang telah melalui kaedah pra-rawat digunakan untuk rawatan pengoksidaan Fenton menggunakan limonit sebagai pemangkin. Kajian ini merupakan kajian pertama yang menggunakan limonit, iaitu sejenis biji limonit yang diperoleh dari Kumamoto, Jepun untuk dinyahwarna. Kajian ini tertumpu penuh untuk menyingkirkan warna POME.

\section{BAHAN DAN KAEDAH}

Bahan kimia bergred analitik digunakan dalam kajian ini termasuk hidrogen peroksida $\left(\mathrm{H}_{2} \mathrm{O}_{2}\right)(30 \%$, Merck), natrium hidroksida $(\mathrm{NaOH})(99 \%$, Sigma Aldrich) dan asid sulfurik $\left(\mathrm{H}_{2} \mathrm{SO}_{4}\right)(95-97 \%$, Merck). Biji limonit yang bersaiz sekitar $4 \mathrm{~mm}$ telah dibekalkan oleh Japan Limonite Pte Ltd, Jepun dan digunakan sebagai pemangkin dalam proses pengoksidaan Fenton. Air ternyahion digunakan untuk semua kerja uji kaji.

Sampel POME yang digunakan dalam kajian ini adalah efluen selepas pra-rawatan secara biologi yang dibekalkan oleh sebuah kilang minyak kelapa sawit di Gua Musang, Kelantan. Ia disimpan di dalam botol plastik dalam peti sejuk pada $4^{\circ} \mathrm{C}$ sebelum digunakan dalam uji kaji. Jadual 1 menunjukkan ciri sampel POME yang diperoleh.

Warna POME sebelum dan selepas rawatan telah diuji menggunakan spektrofotometer UV-Vis (Hach DR 3900) pada panjang gelombang maksimum $454 \mathrm{~nm}$. pH POME diukur menggunakan meter $\mathrm{pH}$ (Euctech). Kandungan oksigen terlarut telah diukur menggunakan alat pengukur oksigen terlarut mudah alih (Hach) menggunakan air suling sebagai sampel kawalan. Bacaan COD dan BOD bagi sampel POME diukur dengan bahan larutan pencernaan (reagen) yang dibekalkan mengikut langkah yang ditentukan oleh American Public Health Association (APHA), American Water Works Association (AWWA) dan Water Environment Federation (WEF).
JADUAL 1. Ciri sampel POME

\begin{tabular}{lc}
\hline Parameter (unit) & POME \\
\hline Warna (PtCo) & $900 \sim 1200$ \\
$\mathrm{pH}$ & 8.38 \\
$\mathrm{DO}(\mathrm{mg} / \mathrm{L})$ & $9-11$ \\
$\mathrm{COD}(\mathrm{mg} / \mathrm{L})$ & $200-300$ \\
BOD $(\mathrm{mg} / \mathrm{L})$ & $110-160$ \\
\hline
\end{tabular}

\section{Uji Kaji Penyahwarnaan Pome}

Sampel POME telah diempar pada kelajuan 12,000 rpm selama 30 min pada suhu $4^{\circ} \mathrm{C}$ menggunakan mesin pengemparan untuk mengasingkan pepejal terampai dalam larutan POME. Uji kaji untuk rawatan POME dijalankan menggunakan sistem kolum yang dilengkapkan dengan pam peristatik dan kolum kaca yang berdiameter dalaman $1 \mathrm{~cm}$ (Rajah 1). Biji limonit dimasukkan ke dalam kolum dengan ketinggian $12 \mathrm{~cm}$. Semua uji kaji telah dijalankan pada suhu bilik. Kadar aliran POME adalah pada $0.2 \mathrm{~mL} /$ min bersamaan dengan masa pengekalan selama 1 jam di dalam kolum. $\mathrm{H}_{2} \mathrm{O}_{2}$ ditambah ke dalam bikar yang mengandungi POME sebelum uji kaji bermula.

Di sepanjang uji kaji rawatan POME, sampel POME (2 mL) telah diperoleh dan dicairkan sebanyak lima kali dan dituras menggunakan membran penapis $(0.45 \mu \mathrm{m})$ sebelum dianalisis menggunakan mesin spektrofotometer. Permintaan oksigen kimia (COD), pepejal terampai (TSS) dan $\mathrm{pH}$ sampel POME sebelum dan selepas rawatan juga telah diukur dalam kajian ini.

\section{Keputusan dan Perbincangan}

Rajah 2 menunjukkan sampel biji limonit mentah yang mempunyai permukaan kasar dan berliang. Keputusan XRF dalam Jadual 2 menunjukkan bahawa $\mathrm{Fe}_{2} \mathrm{O}_{3}$ adalah sebatian utama dalam sampel limonit, iaitu sekitar $70 \%$. Kandungan $\mathrm{Fe}_{2} \mathrm{O}_{3}$ merupakan sumber $\mathrm{Fe}^{2+}$ dan $\mathrm{Fe}^{3+}$ yang bertindak sebagai pemangkin untuk penguraian $\mathrm{H}_{2} \mathrm{O}_{2}$ dan menghasilkan radikal $\mathrm{OH}^{\bullet}$.

JADUAL 2. Sebatian utama yang terdapat dalam biji limonit

\begin{tabular}{cc}
\hline Komposisi & Peratus (\%) \\
\hline $\mathrm{Fe}_{2} \mathrm{O}_{3}$ & 71.04 \\
$\mathrm{SiO}_{2}$ & 12.18 \\
$\mathrm{SO}_{3}$ & 5.26 \\
$\mathrm{CaO}$ & 3.09 \\
\hline
\end{tabular}

\section{Kesan pH ke Atas Pengurangan Warna}

Rajah 3 menunjukkan kesan pH ke atas penurunan warna POME dengan menggunakan $100 \mathrm{mM} \mathrm{H}_{2} \mathrm{O}_{2}$ dan masa 


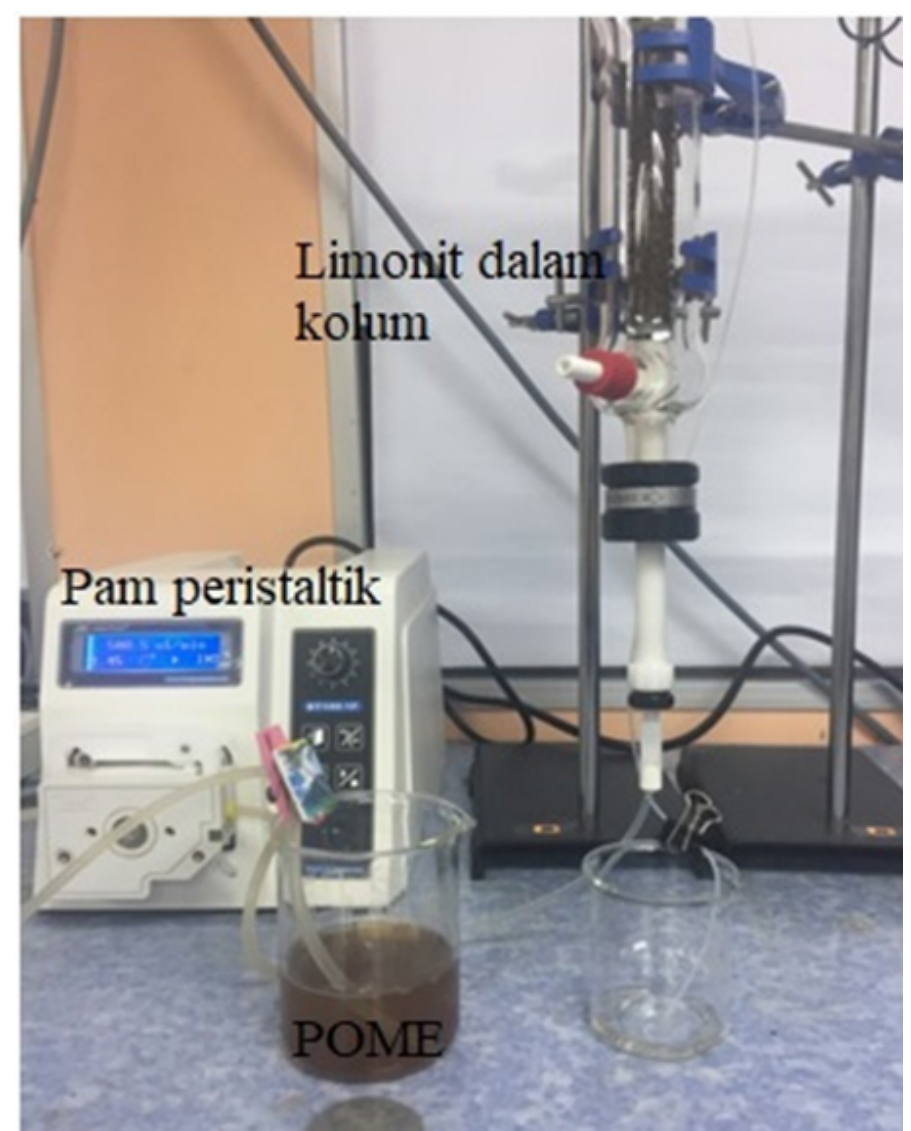

RAJAH 1. Sistem berkolum pengoksidaan Fenton untuk rawatan POME

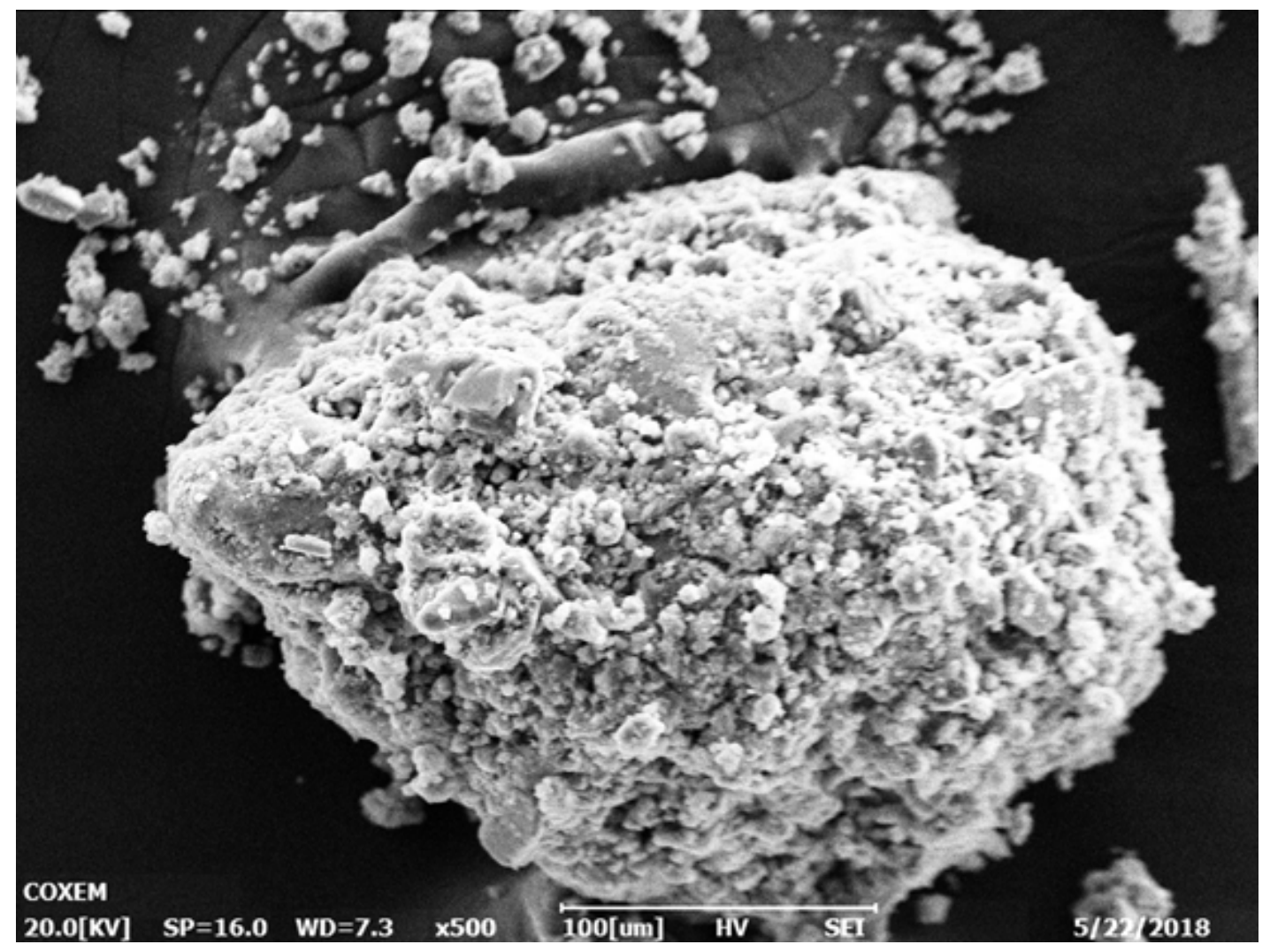

RAJAH 2. Mikroskop Elektron Imbasan biji limonit sebelum digunakan untuk rawatan POME 


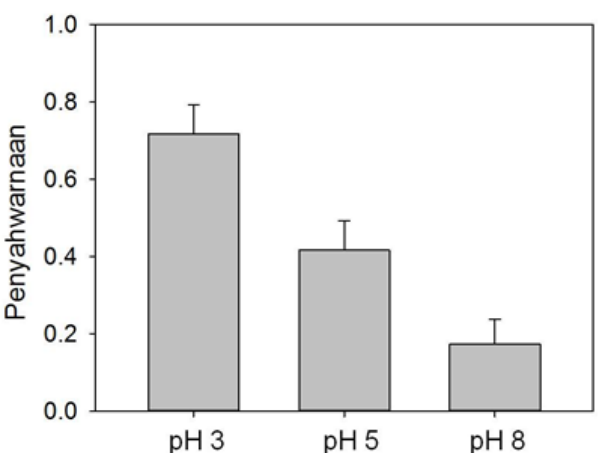

RAJAH 3. Kesan pH kepada penyahwarnaan POME melalui proses pengoksidaan Fenton menggunakan limonit sebagai katalis

pengekalan 1 jam. Keputusan menunjukkan peningkatan dalam kadar pengurangan warna POME dengan peningkatan pH (Alhaji et al. 2016). Daripada graf pada Rajah 3 dapat disimpulkan pada $\mathrm{pH} 3$ kadar pengurangan warna POME adalah paling tinggi. Ini disebabkan pada $\mathrm{pH} 4$ dan ke atas, pemendakan ion besi (limonit) sekaligus merencatkan penghasilan radikal $\mathrm{OH}^{\bullet}$ untuk mengurai molekul sebatian organik warna dalam POME (Kongnoo et al. 2012). Selain itu, julat $\mathrm{pH}$ ini dikaji juga kerana telah diteliti kajian terdahulu yang menyatakan bahawa kereaktifan proses pengoksidaan Fenton dipengaruhi oleh cas zarah pemangkin. Daripada hasil kajian menggunakan Potensi Zeta, limonit bercas positif pada keadaan berasid, ini membantu penghasilan radikal $\mathrm{OH}^{*}$ selepas bertindak balas dengan $\mathrm{H}_{2} \mathrm{O}_{2}$ di dalam kolum (He et al. 2015).

\section{Peranan $\mathrm{H}_{2} \mathrm{O}_{2}$}

Kesan daripada kepekatan $\mathrm{H}_{2} \mathrm{O}_{2}$ di dalam julat $10 \mathrm{mM}$ sehingga $200 \mathrm{mM}$ telah dikaji. Masa pengekalan 1 jam diselaraskan untuk semua uji kaji. Kesan perbezaan kepekatan $\mathrm{H}_{2} \mathrm{O}_{2}$ ke atas pengurangan warna ditunjukkan dalam Rajah 4. Ini disebabkan oleh penjanaan radikal $\mathrm{OH}^{\bullet}$ yang meningkat seiring dengan peningkatan kepekatan $\mathrm{H}_{2} \mathrm{O}_{2}$. Walau bagaimanapun, untuk pH 5 (Rajah 4(a)) pada kepekatan $200 \mathrm{mM} \mathrm{H}_{2} \mathrm{O}_{2}$ bacaan pengurangan menunjukkan prestasi yang sama dengan $100 \mathrm{mM} \mathrm{H}_{2} \mathrm{O}_{2}$, ini menjelaskan penghasilan radikal $\mathrm{OH}^{\bullet}$ berlaku pada paras yang sama dan menunjukkan bahawa $\mathrm{H}_{2} \mathrm{O}_{2}$ yang lebih daripada $100 \mathrm{mM}$ tidak membantu dalam penyahwarnaan (Kallel et al. 2009). Manakala untuk pH 3 (Rajah 4(b)), hanya 100 mM H $\mathrm{H}_{2}$ diperlukan untuk menyahwarna POME. Kadar pengurangan warna (Rajah 5) yang nampak ketara ini adalah kerana pemecahan ikatan dalam kumpulan kromofor oleh radikal $\mathrm{OH}^{\bullet}$ (Kongnoo et al. 2012). Menurut Kongnoo, pigmen organik POME terdiri daripada antosianin, karoten, polifenol, lignin dan tanin. Parameter 10 sehingga $200 \mathrm{mM}$ dipilih kerana berdasarkan stoikiometri tindak balas (Ibrahim et al. 2015):

$1 \mathrm{~g} \mathrm{COD}=1 \mathrm{~g} \mathrm{O}_{2}=0.03125 \mathrm{~mol} \mathrm{O}_{2}=0.0625 \mathrm{~mol} \mathrm{H}_{2} \mathrm{O}_{2}=$ $2.125 \mathrm{~g} \mathrm{H}_{2} \mathrm{O}_{2}$

\section{PermintaAn OKsigen Kimia (COD)}

Beberapa rakan penyelidik telah melaporkan tentang gangguan ukuran nilai COD bagi sampel air yang mengandungi $\mathrm{H}_{2} \mathrm{O}_{2}$ (Lee et al. 2011). Kajian ini tidak terkecuali, walaupun pada permulaan, bacaan COD kelihatan agak rendah, ia meningkat selepas rawatan pengoksidaan Fenton dijalankan. Ini adalah kerana terdapat tindak balas antara baki $\mathrm{H}_{2} \mathrm{O}_{2}$ yang tidak digunakan telah bertindak balas asid kromik dalam bahan kimia pencernaan COD (Zhang et al. 2013). Hal ini dapat diperhatikan pada bacaan COD bagi sampel air suling yang mengandungi $\mathrm{H}_{2} \mathrm{O}_{2}$ seperti yang ditunjukkan dalam Jadual 3. Oleh sebab itu, bacaan COD bagi sampel POME selepas rawatan telah ditolak dengan nilai COD sampel air suling yang mengandungi $\mathrm{H}_{2} \mathrm{O}_{2}$. Walau bagaimanapun, bacaan COD sampel POME selepas rawatan masih lebih tinggi daripada sampel POME asal. Bacaan BOD sampel POME selepas rawatan juga telah diukur tetapi gagal kerana kehadiran $\mathrm{H}_{2} \mathrm{O}_{2}$ yang akan terurai kepada oksigen dan air, dengan kandungan oksigen akan mengganggu bacaan kepekatan oksigen terlarut (Jadual 4). (a)

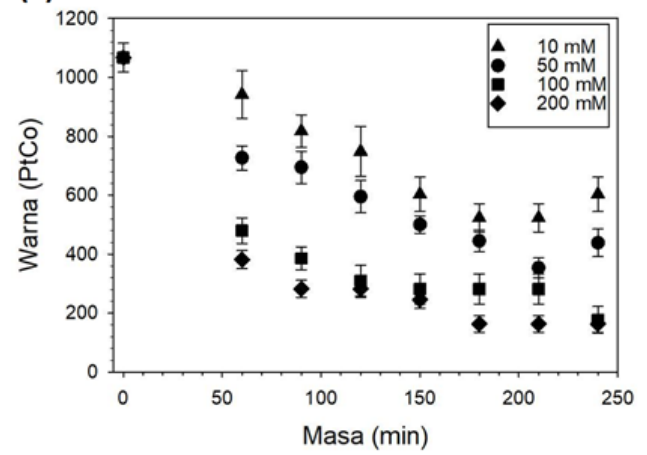

(b)

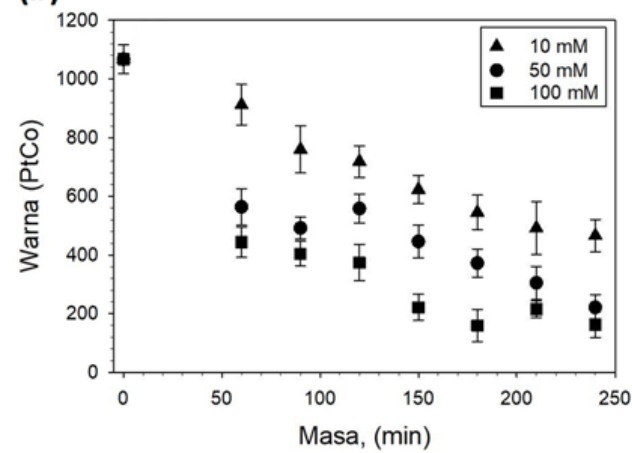

RAJAH 4. Penyahwarnaan POME pada kepekatan $\mathrm{H}_{2} \mathrm{O}_{2}$ yang berbeza pada $\mathrm{pH} 5$ (a) dan $\mathrm{pH} 3$

(b) dengan masa pengekalan 1 jam 


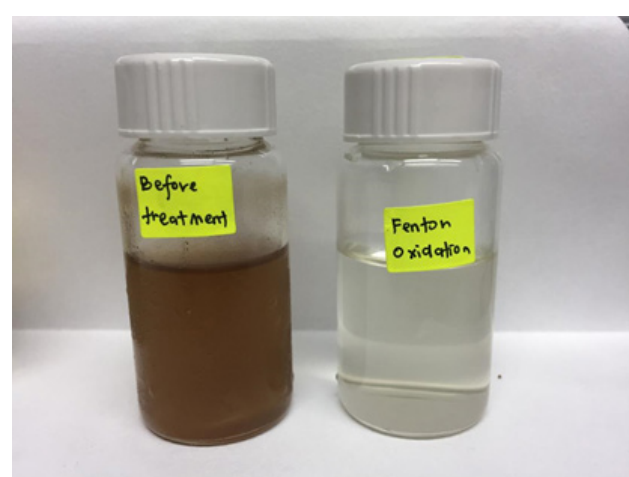

RAJAH 5. Gambar sampel POME sebelum dan selepas rawatan pengoksidaan Fenton $(\mathrm{pH}=3, \mathrm{H} 2 \mathrm{O} 2=50 \mathrm{mM}$, masa pegekalan $=1$ jam $)$

JADUAL 3. Bacaan COD bagi sampel POME sebelum dan selepas rawatan pengoksidaan Fenton pada kepekatan $\mathrm{H}_{2} \mathrm{O}_{2}$ berbeza $(10 \mathrm{mM} \& 50 \mathrm{mM})$

\begin{tabular}{|c|c|c|c|c|}
\hline \multirow[b]{2}{*}{$\begin{array}{l}\mathrm{H}_{2} \mathrm{O}_{2} \\
(\mathrm{mM})\end{array}$} & \multicolumn{4}{|c|}{$\mathrm{COD}(\mathrm{mg} / \mathrm{L})$} \\
\hline & $\begin{array}{l}\text { POME } \\
\text { (sebelum } \\
\text { rawatan) }\end{array}$ & $\begin{array}{c}\mathrm{POME}+\mathrm{H}_{2} \mathrm{O}_{2} \\
(\text { Selepas } \\
\text { rawatan) }\end{array}$ & $\begin{array}{l}\text { Air suling } \\
+\mathrm{H}_{2} \mathrm{O}_{2}{ }^{*}\end{array}$ & $\begin{array}{c}\text { POME } \\
\text { (selepas } \\
\text { rawatan) }\end{array}$ \\
\hline 10 & 202 & 449 & 223 & 226 \\
\hline 50 & 205 & 1420 & 1169 & 251 \\
\hline
\end{tabular}

*Bacaan COD sampel air suling $+\mathrm{H}_{2} \mathrm{O}_{2}$ digunakan untuk tujuan pembetulan kerana kehadiran $\mathrm{H}_{2} \mathrm{O}_{2}$ mengganggu

JADUAL 4. Ciri sampel POME sebelum dan selepas rawatan pengoksidaan Fenton $\left(\mathrm{pH}=3, \mathrm{H}_{2} \mathrm{O}_{2}=50 \mathrm{mM}\right.$, masa pengekalan $=1 \mathrm{jam})$

\begin{tabular}{lcc}
\hline & Sebelum rawatan & Selepas rawatan \\
\hline Warna & $900-1200$ & $100-300$ \\
$\mathrm{pH}$ & 3 & 5 \\
COD & $200-300$ & $220-260$ \\
BOD & $110-160$ & $-*$ \\
TSS & 150 & 20 \\
\hline
\end{tabular}

*Tidak dapat diukur menggunakan meter oksigen terlarut

Bacaan pepejal terampai (TSS) juga menunjukkan penurunan selepas rawatan yang mungkin disebabkan oleh penguraian dan pemecahan sebatian organik telah berlaku. Selepas proses rawatan penyahwarnaan, dapat dilihat nilai pH POME terawat meningkat kepada pH 5 kerana penghasilan $\mathrm{OH}^{-}$dalam proses pengoksidaan Fenton (Ibrahim et al. 2015).

\section{KeSIMPULAN}

Hasil daripada kajian ini menunjukkan bahawa biji limonit berjaya digunakan sebagai pemangkin pepejal untuk penyahwarnaan POME melalui proses pengoksidaan Fenton dengan warna POME adalah sukar disingkirkan melalui proses rawatan secara biologi. $\mathrm{pH} 3$ adalah $\mathrm{pH}$ optimum untuk mencapai tahap penyahwarnaan yang paling tinggi. Kepekatan $\mathrm{H}_{2} \mathrm{O}_{2}$ memainkan peranan penting dalam proses rawatan, tetapi kehadiran baki $\mathrm{H}_{2} \mathrm{O}_{2}$ telah mengganggu penentuan bacaan COD dan BOD. Kajian ini membuktikan bahawa hanya 1 jam masa pengekalan diperlukan untuk menyahwarnakan sepenuhnya POME yang berwarna 8001000 PtCo. Sistem rawatan yang diperkenalkan dalam kajian ini berpotensi untuk merawat POME yang masih berwarna gelap setelah dirawat melalui proses rawatan biologi.

\section{PENGHARGAAN}

Terima kasih kepada Japan Limonite Co. Ltd. atas dana penyelidikan yang diberi. Fazlinda menghargai biasiswa MyPHD yang diberikan oleh Kementerian Pendidikan Malaysia (MOE).

\section{RUJUKAN}

Alhaji, M. H., Sanaullah, K., Lim, S. F., Khan, A., Hipolito, C. N., Abdullah, M. O., Bhawani, S. A. \& Jamil, T. 2016. Photocatalytic treatment technology for palm oil mill effluent (POME) - A review. Process Safety and Environmental Protection 102: 673-686.

Aris, A., Siew, O. B., Kee, K. S. \& Ujang, Z. 2008. Tertiary treatment of palm oil mill effluent using Fenton oxidation. Malaysia Journal of Civil Engineering 20(1): 12-25.

Bhatia, S., Othman, Z. \& Ahmad, A. L. 2007. Coagulationflocculation process for POME treatment using Moringa oleifera seeds extract: Optimization studies. Chemical Engineering Journal 133(1-3): 205-212.

He, R., Tian, B. H., Zhang, Q. Q. \& Zhang, H.T. 2015. Effect of Fenton oxidation on biodegradability, biotoxicity and dissolved organic matter distribution of concentrated landfill leachate derived from a membrane process. Waste Manag. 38: 232-239.

Ibrahim, A. H., Taha, M. R. \& Azhar, A. W. 2015. Removal of COD from palm oil mill effluent (POME) via advanced Fenton process: Optimization study. Advances in Environmental Biology 9(15): 1-10.

Kallel, M., Belaid, C., Boussahel, R., Ksibi, M., Montiel, A. \& Elleuch, B. 2009. Olive mill wastewater degradation by Fenton oxidation with zero-valent iron and hydrogen peroxide. Journal of Hazardous Materials 163(2-3): 550554.

Kietkwanboot, A., Tran, H. T. M. \& Suttinun, O. 2015. Simultaneous dephenolization and decolorization of treated palm oil mill effluent by oil palm fiber-immobilized trametes hirsuta strain AK 04. Water, Air, and Soil Pollution 226: 345 .

Kongnoo, A., Suksaroj, T., Intharapat, P., Promtong, T. \& Suksaroj, C. 2012. Decolorization and organic removal from palm oil mill effluent by Fenton's Process. Environmental Engineering Science 29(9): 855-859.

Lee, E., Lee, H., Kim, Y. K., Sohn, K. \& Lee, K. 2011. Hydrogen peroxide interference in chemical oxygen demand during ozone based advanced oxidation of anaerobically digested livestock wastewater. International Journal of Environmental Science and Technology 8(2): 381-388. 
Neoh, C. H., Lam, C. Y., Lim, C. K., Yahya, A. \& Ibrahim, Z. 2014. Decolorization of palm oil mill effluent using growing cultures of Curvularia clavata. Environmental Science and Pollution Research 21(6): 4397-4408.

Nik Sulaiman, N. M. \& Chea, K. L. 2004. Membrane ultrafiltration of treated palm oil mill effluent (POME). Jurnal Teknologi 41(1): 113-120.

Othman, M. R., Hassan, M. A., Shirai, Y., Baharuddin, A. S., Ali, A. A. M. \& Idris, J. 2014. Treatment of effluents from palm oil mill process to achieve river water quality for reuse as recycled water in a zero emission system. Journal of Cleaner Production 67: 58-61.

Pereira, M. C., Oliveira, L. C. A. \& Murad, E. 2012. Iron oxide catalysts: Fenton and fentonlike reactions-A review. Clay Minerals 47(3): 285-302.

Saeed, M. O., Azizli, K., Isa, M. H. \& Bashir, M. J. K. 2015. Application of CCD in RSM to obtain optimize treatment of POME using Fenton oxidation process. Journal of Water Process Engineering 8: e7-e16.

Sajab, M. S., Chia, C. H., Zakaria, S. \& Sillanpää, M. 2014. Fixed-bed column studies for the removal of cationic and anionic dyes by chemically modified oil palm empty fruit bunch fibers: Single- and multi-solute systems. Desalination and Water Treatment 3994(8): 1-8.

Wu, T. Y., Mohammad, A. W., Jahim, J. M. \& Anuar, N. 2010. Pollution control technologies for the treatment of palm oil mill effluent (POME) through end-of-pipe processes. Journal of Environmental Management 91(7): 1467-1490.

Zhang Qing, Fu Shiyu, Li Hailong \& Liu, Y. 2013. A novel method for the determination of hydrogen peroxide in bleaching effluents by spectrocopy. Bioresources 8(3): 3699-3705.
Nur Fazlinda Razali, Chin Hua Chia* \& Sarani Zakaria

Bioresources and Biorefinery Laboratory

Faculty of Science and Technology

Universiti Kebangsaan Malaysia

43600 UKM Bangi, Selangor Darul Ehsan

Malaysia

Mohd Shaiful Sajab

Research Center for Sustainable Process Technology (CESPRO)

Faculty of Engineering and Built Environment

Universiti Kebangsaan Malaysia

43600 UKM Bangi, Selangor Darul Ehsan

Malaysia

Tatsuya Tobe

Nihon Suido Consultants Co., Ltd.

Shinjuku-ku, Tokyo, 160-0023

Japan

Miku Tsuda

Japan Limonite Co., Ltd.

Aso City, Kumamoto, 869-2235

Japan

*Pengarang untuk surat-menyurat; email: chia@ukm.edu.my

Diserahkan: 25 Disember 2018

Diterima: 10 Oktober 2019 